\title{
The Factors Influencing the Success of Day Surgery at Prince Sultan Military Medical City (PSMMC)
}

\author{
Mohanned Khaled Almarzook $^{1 *}$, Saleh Lafi Alshammari ${ }^{2}$ and Fahad Nasser Alhaqbani ${ }^{3}$ \\ ${ }^{1}$ Senior Physiotherapist, Prince Sultan Cardiac Centre, Saudi Arabia \\ ${ }^{2}$ Medical Devices Specialist, Prince Sultan Cardiac Center, Saudi Arabia \\ ${ }^{3}$ Psychologist, Prince Sultan Cardiac Center, Saudi Arabia
}

*Corresponding author: Mohanned Khaled Almarzook, Senior Physiotherapist, Prince Sultan Cardiac Centre, Saudi Arabia

\section{ARTICLE INFO \\ Received: 幽 November 04, 2020

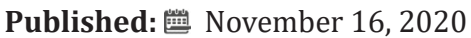

Citation: Mohanned Khaled A, Saleh Lafi A and Fahad Nasser Alhaqbani3. The Factors Influencing the Success of Day Surgery at Prince Sultan Military Medical City (PSMMC). Biomed J Sci \& Tech Res 31(5)-2020. BJSTR. MS.ID.005174.

Keywords: Day Surgery; Success Factors; Health Practitioners; Quality of Medical Care; PSMMC

\begin{abstract}
This study aimed to identify the factors influencing the success of day surgery at Prince Sultan Military Medical City (PSMMC) in Riyadh. The study aimed to identify the effect of (administrative procedures - surgical preparations - medical staff - laboratory and ray equipment, and medical care) on the success of day surgery at Prince Sultan Military Medical City (PSMMC). In order to achieve these goals, the researcher used the descriptive analytical approach and used the questionnaire instrument in order to collect the data from the research sample. Population of the study comprised all the medical staff at PSMMC in Riyadh. The researcher distributed (175) questionnaires on the research sample and (161) questionnaires were put for study. The study concluded that the research sample estimated the administrative procedures with a mean score (3.78), the research sample estimated the surgical preparations with a mean score (3.22), the research sample estimated the medical staff with a mean score (3.41), the research sample estimated the laboratory and ray equipment with a mean score (3.53) the research sample estimated the medical care with a mean score (3.66), and the research sample estimated the success of day cases with a mean score (3.67). Also, the findings showed that there is a correlational relationship between the independent variables and the dependent variable. The study recommended the need to benefit from the international standards in day surgery unit's management to ensure the quality of the health service. The study also recommended establishing a department for the quality and development of day surgery to develop the equipment in day surgery units and to modernize the technological systems that contribute to the provision of high-quality care service.
\end{abstract}

\section{Introduction}

Day surgeries have emerged as a result of the evolution of the health sector in recent years. Day Surgery is a modern program that was introduced several years ago in the United States of America and then began to spread in Europe. Statistics show that $67 \%$ of surgical procedures in America are carried out according to the principle of day surgery [1]. The spread of this type of surgery and the increase in demand is due to several reasons, foremost of which is the advanced medical technology used in day surgery such as laparoscopy, laser, catheter and computer which reduced the surgical incision and minimized the use of scalpel and scissors [2]. The gall bladder now needs a hole no more than one centimeter long. Now, the patients have a desire to reduce the cost of health services arising from their long stay in health facilities. In addition, an important economic benefit is that the individuals return to their work in record time and the preventive factor provided by day surgery. Day surgery minimizes the possibility of transmission of infection among patients [3].

Day surgery is one of the outcomes of the evolution of healthcare institutions in the last 20 years. The idea - applied in several centers in the Kingdom for years - is based on the patient getting out on the same day [4]. The physical cost of entering the patient on the evening of the day prior to the operation and remaining several 
days after the operation was credited with this development as well as the other advantages of day surgery such as the rapid exit of the patient immediately after the operation, reducing the risk of sleep in the bed as well as the risk of transmission of infectious diseases resulting from hospital stay for several days. As expected, this shift in the thinking of medical care institutions has led to an adjustment in the anesthetic approach to these types of surgery to suit the needs and safety of these surgeries. Patients stay in the hospital for several hours after the operation and then go home in their full consciousness, requiring a distinct anesthetic approach for this type of surgeries [1].

According to Mitchell [4], with the tremendous development of anesthesia and patient monitoring techniques, safe and effective anesthesia is available for day surgery patients. It is now available to use modern drugs and techniques to provide quick recovery for patients with very few complications. All surgeries that do not involve the loss of a large amount of blood or that require no care after the surgery can be performed as one day surgeries and that most patients can be treated with the exception of newborns and patients with respiratory problems during sleep.

Deng, et all. [5] emphasize that since quality of service has a pivotal role in the health sector, the quality is of a fundamental importance in the day surgery units in hospitals with the aim of providing superior medical services with the highest quality and speed. Despite the importance of quality of service in day surgery units in hospitals, there are some reasons for the poor quality of service provided at the day surgery units in hospitals. These reasons vary to include poor anesthesia and infrastructure, the insufficient number of employees in day surgery units, the increased number of patients, and the absence of modern medical devices that ensure that the results are delivered quickly and accurately [6].

Many studies have confirmed the importance of quality standards in day surgery units. Jegede, et al. [7] emphasized the importance of a quality management system that ensures the quality of patients' admission procedures, the necessary medical examinations, and the provision of due treatment. Also, $\mathrm{Li}$, et al. [8] demonstrated the role of day surgery units in the diagnosis of diseases and in reducing over-crowdedness in hospitals. Furthermore, Ziab [9] stressed the role of quality management techniques in improving the level of service in day surgery units.

With the current trends of the development of healthcare services in the Kingdom of Saudi Arabia and the new insights provided by Vision 2030 for the provision of high quality and reliable healthcare to all the groups of the Saudi society, the national healthcare institutions are work seriously to provide the most cost and time-effective ways of treatment [2]. However, there are some challenges that face the Saudi national healthcare organizations in the provision of high-quality health care, especially in day surgery units in the governmental hospitals. The study of Al Ahmadi [10] shows that the level of reception and attention in most day surgery units in public hospitals in Saudi Arabia is still poor and not up to the set plans. This does not match with the size of the available resources and the increased demand for high quality services, especially in day surgery units [5].

Day surgery units in hospitals provide highly valuable services to different patients and their success factors should be taken into account in order to provide a distinct health service to the patients. The health care authorities in Saudi Arabia should therefore develop mechanisms to ensure the success of day surgery units in the governmental hospitals. Hence, the current study attempts to study the factors influencing the success of day surgeries in one of the most important governmental health institutions in Saudi Arabia; namely, at Prince Sultan Military Medical City (PSMMC), located in Riyadh city.

\section{Statement of the Problem}

Day surgery units are one of the most important hospital treatment units requiring rapid and accurate delivery of nursing and medical care so that the patients with critical conditions are diagnosed and treated promptly. However, there is a number of problems that face day surgery units in Saudi governmental hospitals such as lack of adequate medical staff and poor management arrangements [11]. Many hospitals also lack control systems and ensure the quality of the day-to-day operation and the absence of regulations that require the application of the quality standards required in day surgery units [6]. All the above problems adversely affect the service provided to the patients with critical conditions and cause many of troubles to the patients who have usual complaints of the type, sufficiency, and preparations of the service at day surgery units in Saudi public hospitals [12].

Since the researcher works in the health sector in Saudi Arabia, he observed some special problems in day surgery units in the Saudi governmental hospitals such as lack of the necessary components for the success of this type of operations such as devices, anesthesia and laboratory preparations, infrastructure, and administrative procedures which negatively affect quality of service provided to the patients. Hence, the problem of the study lies in the following main question:

What are the factors influencing the success of day surgery at PSMMC?

Also, a set of sub-questions can be arisen from the above main question:

1. What is the impact of administrative procedures on the success of day surgery at PSMMC?

2. What is the impact of surgical preparations on the success of day surgery at PSMMC?

3. What is the impact of medical staff on the success of day surgery at PSMMC? 
4. What is the impact of laboratory \& radiology preparations on the success of day surgery at PSMMC?

5. What is the impact of medical care on the success of day surgery at PSMMC?

\section{Objectives of the Study}

This study explores the factors affecting the success of day surgery at PSMMC. The focus on a number of independent variables which include (administrative procedures, surgical preparations, medical staff, laboratory \& radiology preparations, and medical care) and their impact on the dependent variable (the success of day surgery). Based on the research variables, the study aims to achieve the following objectives:

1. To identify the impact of administrative procedures on the success of day surgery at PSMMC.

2. To identify the impact of surgical preparations on the success of day surgery at PSMMC.

3. To identify the impact of medical staff on the success of day surgery at PSMMC.

4. To identify the impact of laboratory \& radiology preparations on the success of day surgery at PSMMC.

5. To identify the impact of medical care on the success of day surgery at PSMMC.

\section{Significance of the Study}

The day surgery units are highly important facilities for the treatment of the patients who suffer from specific conditions in an effective manner. They are essential for the health and safety of patients in need of prompt treatment and quality in the hospitals. The health service in day surgery units plays a major role in saving the lives of the high-risk patients, minimizes the waiting time, reduces the economic costs associated with long stay in the hospitals, and ensures comprehensive treatment for all the patients. However, the day surgery concept is understudied in the context of Saudi Arabia, especially in the governmental and military hospitals. To the researcher's best knowledge, no single study has investigated the factors influencing day surgery in any hospital in Saudi Arabia. The results of this study would help the health authorities and the management of PSMMC to take the best decisions to improve and enhance the best quality services at day surgery units and to ensure that all the human, technological, infrastructure, and administrative resources are available in order to ensure the success of day surgery units in the Saudi hospitals.

\section{Literature Review}

\section{The Concept of Day Surgery}

In general, day surgery can be defined as the type of surgeries in which the patient undergoes a surgery in the hospital or health care centers and leaves in the same day of the surgery. This concept has emerged as a result of the developments in the diagnosis of diseases, the development of medical devices and equipment, and the development of treatment techniques for certain diseases [5]. A number of researchers have introduced definitions to elaborate on day surgery and look deeply in its essence.

Day surgeries are "diagnostic or therapeutic procedures or operations carried out in hospitals and specialized medical centers where the patient comes to the hospital or center and undergoes the operation and then goes to his/her home on the same day without having to be an inpatient" [13]. Also, day surgeries can be defined as "possible medical operations for the patient in the morning and return to normal status safely and with minimal pain" [9].

The day surgery is "the type of surgery in which the patient enters the hospital or the specialized center for the operation and return home in the same day" [14]. With the great development of anesthesia and patient monitoring techniques, it is now possible to provide safe and effective anesthesia for patients who have a day surgery. It is now possible to use modern drugs and techniques to provide quick recovery for patients with very few complications such as nausea and pain. Doran, et al. [15] believe that all operations that do not have a large blood loss or that do not require postoperative care can be performed as day surgeries and most patients can be treated except newborns and patients with respiratory problems during sleep.

Al Ahmady [10] informed about the equipment and preparations that should be available in a day surgery unit in the Kingdom of Saudi Arabia. He reported that a typical day surgery unit should have or should be equipped with the following supplies:

1. The person performing the operation under general anesthesia must not be less than a consultant.

2. A day surgery permit is granted to a Saudi consultant in his field of specialization.

3. Specialized personnel should be available in terms of the technicians, nurses and operating rooms.

4. The specialized day surgery clinic should have all the equipment needed for CPR and to include a portable ventilator.

5. For a non-Saudi physician, he/she must be a consultant and have a valid professional license and annual contract. $\mathrm{He} /$ she must have insurance against medical errors valid six months after his departure. The day surgery center should be responsible for any complications that may result from the operation due to medical error or negligence.

6. The medical team must have a certified cardiopulmonary resuscitation course. 


\section{Success Factors of Day Surgeries}

Several researchers have discussed the success factors of day surgeries. In general, the majority of the researchers should have the surgical tools, equipment, infrastructure, and personnel needed to perform the day surgery in a staying manner. To start with Deng [5] informed that surgical factors are the essential requirements for day surgeries. The appropriate surgical factors enhance the success of day surgeries include the following [5]:

1. The procedure should not have significant risk of major postoperative complications necessitating immediate medical intervention (hemorrhage, cardiovascular instability).

2. No prolonged specialist postoperative care or observation required.

3. Abdominal and thoracic cavities should only be opened with minimally invasive techniques.

4. Postoperative pain should be controllable with oral anaesthesia techniques.

5. Patient should be able to rapidly resume normal functions (oral nutrition, safe mobilization).

6. Urgent procedures are also appropriate for a semielective day-case pathway, for example, drainage of abscesses, some trauma surgery.

Also, preoperative preparation is a key element in day surgery. Ansell \& Montgomery [16] stated that successful day surgery outcomes require good preoperative preparation. This has three essential components:

a) Education of patients and carers about day surgery pathways.

b) Helping patients to make informed decisions by providing verbal and written information regarding planned procedures and postoperative care.

c) Identification of any medical risk factors and optimizing medical conditions before surgery.

According to Montgomery [17], preoperative assessment should ideally occur as close to the decision to treat as possible to give maximum time for optimization of medical conditions, hence reducing the risk of cancellation. If possible, it should take place within the day-case unit, allowing patients and their relatives to become accustomed to this environment and staff before the day of surgery. A nurse delivered, consultant supported preoperative assessment service is the most common model with protocols for investigations, management of medications, and other issues.

A further success factor is Anaesthetic management. Fehrrman, et al. [1] report that the key requirements of a day surgery anaesthetic agent include:
1. Rapid onset and offset of anaesthesia with clear-headed emergence.

2. Minimal postoperative nausea and vomiting, dizziness or drowsiness.

3. Rapid return to full cognitive functions.

While these are properties desirable for all anaesthetic techniques, they are particularly important in the day surgery patient due to the requirement for rapid return to oral nutrition, mobilization, and full cognitive function [18]. The fundamental elements in delivering high-quality day surgery anaesthesia are attention to detail in all aspects of the anaesthetic technique. Shortacting agents, supplemented by local anaesthetic techniques and simple oral analgesia, protocol-driven use of anti-emetic medication where required, minimal starvation times, and judicious use of fluids are the key to success [19]. Day surgery patients have a finite time on the day surgery unit before discharging that same day. Therefore, prompt management of pain and nausea and vomiting and early mobilization are paramount. A more rapid recovery from anaesthesia results in quicker turnaround, improved patient experience, and reduced costs [20].

Doyle and Saunders [21] explored that postoperative recovery and discharge as key success factors of day surgery. They maintained that during the postoperative period, patients should be actively encouraged to return to their preoperative physiological state. Experienced nursing staff trained in the practice of day surgery is essential to ensure smooth progression of patients along the day surgery pathway and the rapid turnover which is required to run an efficient unit. Staff should ideally be trained to remove an advanced airway, allowing for a more rapid transfer from theatre and continuation with the next case. Also, modern drugs and surgical techniques may allow such a rapid recovery. The patients should only remain in recovery as long as is necessary to retain full consciousness and have immediate analgesic requirements met. Acute symptoms such as pain and nausea and vomiting should be treated quickly with simple oral analgesia supplemented by shortacting opiates if required [22].

Finally, Davies, et al. [18] introduced the organizational and administrative factors as essential elements in day surgery. They stated that every hospital should have a dedicated day surgery unit. Dedicated day surgery lists in autonomous units provide the best model of care and avoid tension from competing interests of mixed in-patient and day-care lists. Each day surgery unit should have a medical clinical lead, unit nurse manager, and administration support. Equipment, monitoring, and staffing and recovery areas should be of the same standard as in-patient facilities. Surgeons (2012) concluded that continuous audit of patient outcomes is essential to providing high-quality day surgery services and driving continuous improvement. 


\section{Empirical Research}

Many researchers have tackled the day surgery and the factors affecting it. This issue was addressed from different perspectives and from the viewpoint of a different sample. Below are some of the studies that are considered relevant to the topic of the current study with efforts to link this study to the literature of day surgery. Li, et al. [8], in a study titled "The Effect of Laboratory Testing in Day Case clinics: A Multihospital Longitudinal Study Applying a Cross-classified Random-effect Modeling Approach", examined the relationship between laboratory tests and the success of day surgery using a set of patient data from 4 hospitals over a period of 4 years. The retrospective approach was used in four-day surgery 『 clinics in New South Wales, Australia from 2008 to 2009. Data was extracted from the information systems of day surgery clinics in hospitals. The random effect method was used to identify the factors affecting the medical examinations in day surgery clinics. The results of the study showed that the faster the laboratory tests are delivered, the greater is the success rate of the operations per day. The study also found that the patients who are admitted to day surgery clinics choose the places that are characterized by quality in medical examinations. The study recommended increasing the number of medical staff in day surgery clinics and increasing the number of day surgery rooms.

Chinamale [23] conducted a study titled, "An investigation of the status of quality assurance and quality control measures in X-ray departments in Malawi" to evaluate quality assurance procedures at day surgery centers in Malawi as well as wide exit fees to build recommendations for a quality system at day-surgery centers at Malawi hospitals. To collect the data from the study sample, the researcher used the analytical descriptive method and used the questionnaire to collect the data from the sample of the study. The study sample consisted of (4) central hospitals and (10) hospitals in the cities. The questionnaire was distributed on the medical staff in the day-surgery centers in the sample hospitals. The participants revealed that the day-surgery centers do not contain sections for quality control and assurance. These centers do not contain any quality control and assurance committees. The study also found that the level of radiology devices in all day surgery centers was very poor. The study recommended the establishment of quality control and quality assurance committees to encourage the application of quality standards in day-surgery centers.

Odhiambo, et al. [24] conducted a study titled, "Utilization of day surgery services at Upper hill Medical Centre and the Karen hospital in Nairobi: the influence of medical providers, cost and patient awareness" sought to establish how utilization of day surgery services was influenced by medical providers, patient awareness and cost among other factors. The study design was cross sectional with self-administered questionnaires used to collect data. The findings of the study showed that most doctors were aware of day surgery services, but their frequency of utilization was low. Furthermore, medical insurance providers approved only half of the requests for day surgery. Doctors' employees were aware of the services and most of them would recommend it to patients. Although, most patients were not aware of day surgery services those who were aware would prefer day surgery to in patient. Moreover, doctors and medical insurance providers considered day surgery to be cheaper than in patient.

Gilliard, et al. [25] in their study titled, "A methodology to estimate the potential to move inpatient to one day surgery", presented a methodology to estimate the potential to move inpatient to one day surgery. They proposed an algorithmic method, using only routinely available hospital data to identify surgical hospitalizations that could have been performed as one day treatment. The results showed that the proposed approach allows the monitoring of the proportion of inpatient stay candidates for one day surgery. It could be used for infrastructure planning, resources negotiation and the surveillance of appropriate resource utilization.

Stessel, et al. [26] conducted a study titled "Prevalence and Predictors of Quality of Recovery at Home after Day Surgery" to analyze prevalence and predictors of quality of recovery $\gg$ after day surgery on the fourth postoperative day at the Maastricht University Medical Center. Elective patients scheduled for day surgery from November 2008 to April 2010 were enrolled in a prospective cohort study. A total of 1118 patients were included. The findings showed that the best predictor for poor quality of recovery after day surgery was type of surgery. Other predictors were younger age, work status, and longer duration of surgery. A history of previous surgery expected pain (by the patient) and high long-term surgical fear were significant predictors of poor quality of recovery.

Singarelli, et al. [27] conducted a study titled "Day-surgery, oneday surgery: the experience of an ENT unit in a 250-bed hospital" to discuss the factors affecting day surgery. A retrospective study on personal experience of day-surgery procedures from 1st January 2002 to 31st December 2004 is presented. The study comprises 1077 patients (74.2\%) out of 1452 hospitalisations for programmed surgery in this period. The findings of the study highlighted the importance of communication for an active and responsible involvement of the patients: the human factor is an indispensable quality for the good outcome of the procedure. The above empirical studies have addressed day surgery from different aspects. Each of these studies aimed to identify an important aspect of quality of service in day surgery clinics in order to gain a deep understanding of the components that affect day surgery. The present study is similar to the study of $\mathrm{Li}$, et al. [8] since the two studies examine laboratory services in day surgery clinics. It is also similar to the study of Chinamale [23] that focused on the radiology 
service, but the current study is extended to various variables such as administrative procedures, surgical equipment, medical staff, laboratory and radiation equipment, and medical care.

On the other hand, the current study differs with the study of Singarelli, et al. [27] that was conducted on an ENT unit, but the current study focuses on all day surgery units at PSMMC. Also, Stessel, et al. [26] examined prevalence and predictors of quality of recovery at home after day surgery and Gilliard, et al. [25] proposed a methodology to estimate the potential to move inpatient to one day surgery. Furthermore, Odhiambo, et al. [24] discussed how utilization of day surgery services was influenced by medical providers, patient awareness and cost. The present study offers a set of new variables examined in none of the above studies.

Based on the above literature, the current study, according to the researcher's best knowledge, is the first of its kind to study the factors affecting the success of day surgeries at PSMMC in Riyadh, Saudi Arabia. Thus, the present study seeks to bridge an academic gap by discussing an understudied topic in the Saudi health care context.

\section{Methodology}

\section{Research Approach}

This research is based on the descriptive analytical approach. The description in its comprehensive sense is "to obtain information related to the current state of the phenomenon under study in order to determine the nature of this phenomenon and to identify the interrelationship in the occurrence of this phenomenon, its description, perception and analysis of the variables affecting the emergence and growth" [28]. The descriptive approach is based on the study of reality and expressing in a qualitative or quantitative manner. While the qualitative approach describes the phenomenon and demonstrates its characteristics, the quantitative approach describes the phenomenon in numbers and explains its size or volume and degrees of correlation with other phenomena.

\section{Population and Sample}

The research population consist of all medical staff at day surgery unit in Prince Sultan Military Medical City (PSMMC), Riyadh city in the Kingdom of Saudi Arabia in the second semester of the academic year (2018 - 2019). The study population consist approximately of (175) medical employees. The study sample consists of all the population members using the complete census method. The participants who already participated in the study and provided valid responses were (161) participants.

\section{Research Instrument}

The questionnaire was used to collect data and to answer the research questions. A questionnaire is a necessary data collection tool consisting of a set of questions directed at the research sample in order to collect data about the studied topic. It is in the form of a number of questions to identify the views of participants of the factors influencing the success of day surgery at Prince Sultan Military Medical City (PSMMC). Below is a description of the research questionnaire.

The questionnaire consisted of two main parts:

Part one: the personal information of the participants. It comprises the following variables:

(Age - Gender - Education - Job /Specialization - Number of years of experience in the hospital)

Part two: the factors influencing the success of day surgery. This section consists of six sub-sections:

1. The first section: It is about administrative procedures and consists of (9) items.

2. The second section: It is about surgical preparations and consists of (8) items.

3. The third section: It is about the medical staff and consists of (6) items.

4. The fourth section: It is about laboratory and radiology preparations and consists of (8) items.

5. The fifth section: It is about medical care and consists of (6) items.

6. The sixth section: It is about the success of day surgery and consists of (6) items.

The five-digit Likert scale was used to respond to the questions and the answer to each item were 5 options, from (1-5), where " 5 " means a strong agreement and " 1 " means strong disagreement.

\section{Validity of the Questionnaire}

The validity of the questionnaire is to measure the suitability of the questionnaire to its purposes. The researcher achieved the validity of the questionnaire by means of the validity of the arbitrators. The researcher presented the questionnaire to a group of arbitrators. The researcher responded to the opinions of the arbitrators and made the necessary deletions and amendments in the light of the submitted remarks.

\section{Reliability of the Questionnaire}

Reliability means that the questionnaire will give the same results if the questionnaire is redistributed more than once under the same conditions. In other words, the reliability of the questionnaire means stability in the results of the questionnaire and that the findings do not change significantly if it is redistributed to the sample several times over time. The researcher verified the reliability of the questionnaire using the split-half method. The questionnaire items were divided into two parts of odd and even numbered questions. The correlation coefficient between the 
scores of the odd questions and the even question scores was then calculated. The coefficient of correlation with Spearman Brown was calculated as follows:

\section{Statistical Treatment}

In order to answer the questions of the study, the statistical data collected through the questionnaire was processed statistically

Table 1: Characteristics of the Research Sample.

\begin{tabular}{|c|c|c|}
\hline Percentage & Frequency & Gender \\
\hline $85.7 \%$ & 138 & Male \\
\hline $14.3 \%$ & 23 & Female \\
\hline $100 \%$ & 161 & Total \\
\hline Percentage & Frequency & Age \\
\hline $6.8 \%$ & 11 & Less than 25 years \\
\hline $37 \%$ & 60 & From 25 to less than 30 years \\
\hline $24 \%$ & 39 & From 30 to less than 35 years \\
\hline $16 \%$ & 26 & From 35 to less than 40 years \\
\hline $15 \%$ & 25 & More than 45 years \\
\hline $100 \%$ & 161 & Total \\
\hline Percentage & Frequency & Years of Experience \\
\hline $14 \%$ & 23 & Less than 5 years \\
\hline $57 \%$ & 93 & From 5 to less than 10 years \\
\hline $21 \%$ & 35 & From 10 to less than 15 years \\
\hline $6 \%$ & 10 & More than 15 years \\
\hline $100 \%$ & 161 & Total \\
\hline Percentage & Frequency & Education \\
\hline $15 \%$ & 25 & Diploma \\
\hline $69 \%$ & 112 & Bachelor \\
\hline $10 \%$ & 16 & Higher Studies \\
\hline $5 \%$ & 8 & Other \\
\hline $100 \%$ & 161 & Total \\
\hline Percentage & Frequency & Job/specialization \\
\hline $23 \%$ & 37 & Physician \\
\hline $28 \%$ & 45 & Nursing \\
\hline $30 \%$ & 48 & Technician \\
\hline $19 \%$ & 31 & Specialist \\
\hline $100 \%$ & 161 & Total \\
\hline
\end{tabular}

\section{Results and Discussion}

This part presents an analysis of the collected data and the results of the study based on the questionnaire distributed on the research sample. Also, the below part presents the discussion of results and the statistical analysis.

\section{Characteristics of the Research Sample}

The findings of the first part of the questionnaire are shown in the below Table 2 . These results relate to the demographics and job variables of the research sample. using the SPSS program. The following statistical methods were used: the frequency, percentages, the standard deviations, the split half method to determine the reliability of the questionnaire, the relative weight for each item of the questionnaire, and Chi-square $(\chi 2)$ to clarify the differences between the responses.

The results shown in Table 1 indicate that the Spearman Brown correlation coefficient is acceptable and statistically significant 
period of less than five years is $14 \%$, the percentage of those who served in the hospital from 5 years to less than 10 years is about $57 \%$ of the total number of sample, the percentage of those who served in the hospital from 10 to less than 15 years is $21 \%$ of the total sample, and those who served more than 15 years are $6 \%$ of the entire respondents.

Table 2: Analysis of Section One (Administrative Procedures).

\begin{tabular}{|c|c|c|c|c|c|}
\hline Items & Mean & Relative Weight & Chi-Square $\chi^{2}$ & DF & Sig. \\
\hline $\begin{array}{c}\text { There is a hospital-approved mechanism for coordinating day surgeries and } \\
\text { processing reservations. }\end{array}$ & 3.66 & 67.02 & 9.008 & 2 & 0.000 \\
\hline $\begin{array}{l}\text { The surgeon informs the operations ward of the date, type and requirements of } \\
\text { the surgery. }\end{array}$ & 4.40 & 75.19 & $14.354^{* *}$ & 2 & 0.000 \\
\hline There is an office to make the patient registration and process approval forms. & 4.21 & 77.23 & 6.020 & 2 & 0.000 \\
\hline Patient admission procedures for day surgery rooms are easily made. & 3.23 & 77.44 & 3.547 & 2 & 0.000 \\
\hline Confirmation is made with the patient for the place and type of the operation. & 4.04 & 74.23 & 13.683 & 2 & 0.063 \\
\hline $\begin{array}{l}\text { The patient's data, the required tests, and the decision to perform the surgery } \\
\text { are reviewed. }\end{array}$ & 3.84 & 75.23 & $15.861^{* *}$ & 2 & 0.000 \\
\hline The patients' medical history are checked and they themselves are scrutinized. & 3.47 & 76.02 & $12.384^{* *}$ & 2 & 0.000 \\
\hline The patient is informed of the day of surgery. & 4.02 & 79.22 & $9.006^{* *}$ & 2 & 0.001 \\
\hline $\begin{array}{l}\text { There is a coordination between day surgery clinics and other clinics in the } \\
\text { hospital. }\end{array}$ & 3.21 & 77.21 & $* 21.756$ & 2 & 0.022 \\
\hline Total Mean & \multicolumn{5}{|c|}{3.78} \\
\hline
\end{tabular}

Note: *Significant at less than (0.05), **Significant at less than (0.01).

In terms of the education variable, the percentage of those who hold a diploma certificate is (15\%), the percentage of the respondents who have a bachelor degree is (69\%), the number of those who have higher studies is $(10 \%)$, and the percentage of holders of other certificates is (5\%). As for the job/specialization variable, the percentage of the respondents who are physicians is $(23 \%)$, the number of those who are nurses is (28\%), and the percentage of those who are technicians are (30\%), and those who are specialists are (19\%).

\section{Results of the First Section}

The first section of the questionnaire is about the administrative procedure's variable. Below are the responses of the participants to the items of this section:
The above Table 3 shows the responses of the participants to administrative procedures. In general, the mean of all items (administrative procedures) is (3.78) and the significance level is 0.000 , indicating that the participants highly agree on this section. The results show that the administrative procedures of day surgery in the hospital are conducted in a good manner in terms of the existence of a specific mechanism for the arrangement and coordination of surgery and patient registration and follow up procedures that precede the surgery. The results also revealed that there is a system for informing patients of surgical instructions, communication between the surgeon and the operations ward, double-checking of the patient's information and that the entry procedures are easy.

Table 3: Analysis of Section Two (Surgical Preparations).

\begin{tabular}{|c|c|c|c|c|c|}
\hline Items & Mean & Relative Weight & Chi-Square $\chi^{2}$ & DF & Sig. \\
\hline The necessary tests and vital signs-taking are performed before the operation. & 3.98 & 74.11 & *11.354 & 2 & 0.034 \\
\hline $\begin{array}{l}\text { The patient shall not be admitted to the operations until after the completion of } \\
\text { all tests and declarations. }\end{array}$ & 3.21 & 77.23 & 6.020 & 2 & 0.000 \\
\hline $\begin{array}{c}\text { Anesthesia is initiated after ensuring that the surgeon, assistant nurse and } \\
\text { anesthesiologist are present and ready to work. }\end{array}$ & 3.22 & 71.66 & *16.861 & 2 & 0.005 \\
\hline Anesthesia options and side effects are explained to the patient. & 3.23 & 77.44 & 2.327 & 2 & 0.000 \\
\hline $\begin{array}{c}\text { The patient's knowledge of the type and position of the surgery is confirmed } \\
\text { verbally. }\end{array}$ & 3.12 & 78.33 & 2.075 & 2 & 0.000 \\
\hline $\begin{array}{l}\text { Day surgery clinics have all the tools used (sterilization indicators, fixtures, } \\
\text { appliances, surgical instruments, etc.) and in a sufficient manner. }\end{array}$ & 3.02 & 71.66 & $* 16.861$ & 2 & 0.005 \\
\hline $\begin{array}{l}\text { It is ascertained that the required rays and their results are present with the } \\
\text { patient in the operating room and have been well reviewed. }\end{array}$ & 2.97 & 76.02 & $12.384^{* *}$ & 2 & 0.000 \\
\hline Security and safety standards are applied at all stages of day surgery. & 3.01 & 78.23 & *16.391 & 2 & 0.012 \\
\hline Total Mean & \multicolumn{5}{|c|}{3.22} \\
\hline
\end{tabular}

Note: *Significant at less than (0.05), **Significant at less than $(0.01)$. 
The previous finding is consistent with Doyle \& Saunders [21] and Currie, et al. [13] who reported that work procedures in hospitals depend on coordination, organization, follow-up and management of all elements of the system by professional staff. The previous finding differs from the findings of Stessel, et al. [26] who reported the absence of regulations and policies governing day surgery in governmental hospitals. The previous finding also confirms the findings of the Beamont [1] study that day surgery requires a high level of coordination and follow-up where many specialties and many hospital units are involved. Day surgeries take place in a short time and thus require a reduction of many routine Table 4: Analysis of Section Three (Medical Staff). procedures adopted in government hospitals.

\section{Results of the Second Section}

The second section of the questionnaire is about surgical preparations variable. Below are the responses of the participants to the items of this section:

The above Table 4 shows the responses of the participants to surgical preparations. In general, the mean of all the items (surgical preparations) is (3.22) and the significance level is 0.000 . This means that the participants agree on the items of this section.

\begin{tabular}{|c|c|c|c|c|c|}
\hline Items & Mean & Relative Weight & Chi-Square $\chi^{2}$ & DF & Sig. \\
\hline $\begin{array}{l}\text { Day surgery clinics have all the necessary human resources (surgeon, } \\
\text { anesthesiologist, nurses, technicians, etc.). }\end{array}$ & 3.55 & 70.36 & $11.989 *$ & 2 & 0.024 \\
\hline $\begin{array}{l}\text { Day surgery professionals have the appropriate qualifications for this kind of } \\
\text { intervention. }\end{array}$ & 3.91 & 74.23 & 13.683 & 2 & 0.000 \\
\hline The clinic staff have good experience in day surgery. & 3.16 & 74.23 & $* * 21.658$ & 2 & 0.000 \\
\hline The number of the medical staff in day surgery units suits the work load. & 4.09 & 67.02 & 9.008 & 2 & 0.000 \\
\hline $\begin{array}{l}\text { Laboratory staff have the full desire to serve the patients without any boredom } \\
\text { or delay. }\end{array}$ & 3.31 & 77.23 & 6.020 & 2 & 0.000 \\
\hline The medical staff get training on this type of surgeries. & 2.45 & 77.11 & $* * 9.501$ & 2 & 0.000 \\
\hline Total Mean & 3.41 & 76.02 & $12.384^{* *}$ & 2 & 0.000 \\
\hline The patient is informed of the day of surgery. & 4.02 & 79.22 & $9.006^{* *}$ & 2 & 0.001 \\
\hline $\begin{array}{l}\text { There is a coordination between day surgery clinics and other clinics in the } \\
\text { hospital. }\end{array}$ & 3.21 & 77.21 & $* 21.756$ & 2 & 0.022 \\
\hline Total Mean & \multicolumn{5}{|c|}{3.78} \\
\hline
\end{tabular}

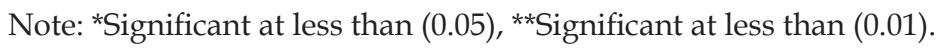

The results show that the surgical preparations of day surgery at PSMMC are conducted in a good manner. It is shown that the necessary tests and biometrics are performed before the operation and that the anesthesia options and the side effects of the patient are explained. The participants also expressed that it is assured that he surgeon, assistant nurses and anesthesiologists are present and ready to work. . The results also showed that the units of day surgery in the hospital have the examination materials and devices in terms of availability of various types of needles, measuring tools, medical labels and various modern inspection devices. This result is in line with the findings of Singarelli, et al. [27] who concluded that medical equipment in day surgery units contribute to improving hospital performance and improving the level of services provided to the patients. This finding also corresponds with the findings of the Chinamale [23] that surgery units should be provided with modern equipment in order to enhance the patient's satisfaction of the provided service.

\section{Results of the Third Section}

The third section of the questionnaire is about medical staff variable. Below are the responses of the participants to the items of this section:

The above Table 5 shows the responses of the participants to medical staff. In general, the mean of all items (medical staff) is (3.41) and the significance level is 0.000 . This indicates that the participants agree on the items of this section.

It is clear from the previous results that the staff at day surgery units at PSMMC have good qualifications and a good level of scientific experience and knowledge that suits the nature of their work. The findings also show that the staff observe the conditions of occupational health. This result is in line with the findings of Odhiambo et al. [24] and Montgomery [17] that the human element is the most important element in the health service where the success of the health service depends on the experiences and qualifications of the health staff and the way they deal with the patients. This finding also matches with the study of Li, et al. [8] that hospitals should care for health personnel and provide an appropriate work environment both internally and externally. 
Table 5: Analysis of Section Four (Laboratory and Radiology Preparations).

\begin{tabular}{|c|c|c|c|c|c|}
\hline Items & Mean & Relative Weight & Chi-Square $\chi^{2}$ & DF & Sig. \\
\hline The hospital radiology room is designed according to the required standards. & 3.39 & 75.19 & $14.354^{* *}$ & 2 & 0.000 \\
\hline The radiology department has the recent medical devices. & 3.61 & 77.23 & 6.020 & 2 & 0.000 \\
\hline $\begin{array}{l}\text { Various types of samples are withdrawn at the hospital and sterilized according } \\
\text { to the required specifications. }\end{array}$ & 3.23 & 73.44 & 3.547 & 2 & 0.000 \\
\hline The patient can perform all kinds of medical tests at the hospital. & 3.87 & 74.23 & 13.683 & 2 & 0.063 \\
\hline The radiology department contains the necessary equipment. & 3.61 & 74.23 & $* * 21.658$ & 2 & 0.000 \\
\hline The hospital has the CT scan and comprehensive scanning devices. & 3.81 & 70.36 & $11.989 *$ & 2 & 0.030 \\
\hline Radiations and surgery are performed at the hospital without delay. & 3.41 & 74.23 & 13.683 & 2 & 0.003 \\
\hline The results of radiation and the hospital are accuracy and quality. & 3.36 & 70.96 & $2.126^{* *}$ & 2 & 0.000 \\
\hline Total Mean & \multicolumn{5}{|c|}{3.53} \\
\hline
\end{tabular}

Note: *Significant at less than (0.05), **Significant at less than (0.01).

\section{Results of the Fourth Section}

The fourth section of the questionnaire is about laboratory and radiology preparations variable. Below are the responses of the participants to the items of this section:

The above Table 6 shows the responses of the participants to laboratory and radiology preparations. In general, the mean of all items (laboratory and radiology preparations) is (3.53) and the significance level is 0.000 indicating that the participants highly agree on laboratory and radiology preparations. The results show that laboratory and radiology facilities in day surgery units are well-equipped. The patient can perform all kinds of medical tests Table 6: Analysis of Section Five (Medical Care). at the hospital with the presence of different radiology devices and various measurements. The study also showed that the day surgery units have the modern equipment and that the service is provided quickly and without delay. These results are consistent with the results Doyle \& Saunders [21] and Currie, et al. [13] who confirmed that the quality of laboratory and radiation units depends on the existence of a physical environment conforming to medical specifications and the existence of systems that ensure the efficiency of work quickly and smoothly. The results of this study are in line with the results of the Ziab [9] which indicated that patients' satisfaction of the services of medical laboratories.

\begin{tabular}{|c|c|c|c|c|c|}
\hline Items & Mean & Relative Weight & Chi-Square $\chi^{2}$ & DF & Sig. \\
\hline $\begin{array}{c}\text { The surgeon, anesthetist, and nurse review the key points of medical care } \\
\text { during recovery. }\end{array}$ & 3.26 & 74.23 & $* * 21.658$ & 2 & 0.000 \\
\hline $\begin{array}{c}\text { The safety of the patient is monitored during the whole period of his stay in the } \\
\text { operations wing and the room of the patient. }\end{array}$ & 3.91 & 67.02 & 9.008 & 2 & 0.000 \\
\hline $\begin{array}{l}\text { The efficiency of surgical operations during and after the patient's stay in the } \\
\text { patient's room is monitored. }\end{array}$ & 3.52 & 77.22 & 6.021 & 2 & 0.000 \\
\hline The hospital has all kinds of medicines needed for one day surgeries. & 2.98 & 77.24 & 3.547 & 2 & 0.000 \\
\hline A full nursing service is provided to the patient until he leaves the hospital. & 4.02 & 73.33 & $0.069^{* *}$ & 2 & 0.000 \\
\hline The patient is acknowledged of treatment instructions. & 4.31 & 74.11 & $3.594^{* *}$ & 2 & 0.000 \\
\hline Total Mean & \multicolumn{5}{|c|}{3.66} \\
\hline
\end{tabular}

Note: *Significant at less than (0.05), **Significant at less than (0.01).

This finding is also consistent with Montgomery' [17] assertion that laboratory and radiation preparations are vital processes in health organizations and essential for disease diagnosis and treatment. This finding is in line with the findings of the Jegede et al. [7] who concluded that patients' satisfaction of the quality of laboratory and radiation depends on the quality of patient's blood sampling and sterilization and hygiene procedures.

\section{Results of the Fifth Section}

The Fifth section of the questionnaire is about the medical care variable. Below are the responses of the participants to the items of this section:
The above Table 7 shows the responses of the participants to the medical care. In general, the mean of all items (medical care) is (3.66) and the significance level is 0.000 . This indicates that the participants highly agree on the medical care in the hospital.

The previous finding shows that the medical care provided at day surgery units at PSMMC is satisfying from the respondents' perspective. It is expressed that the nursing service is provided to the patient permanently with the provision of the necessary tools with continuous follow-up by the surgeon, the assistant doctors and technicians as well as the guidance of the patient in relation to treatment instructions. This result matches with the findings of 
Stessel, et al. [26] who emphasized that the outstanding medical care contributes to increasing the patients' trust in the hospital and to improving the health of patients. The results of this study are also Table 7: Analysis of Section Six (Success of Day Surgery). consistent with the results of the Jegede, et al. [7] that stressed the importance of continuous follow-up of the patient and the taking of vital signs at short intervals in day surgeries $[27,28]$.

\begin{tabular}{|c|c|c|c|c|c|}
\hline Items & Mean & Relative Weight & Chi-Square $\chi^{2}$ & DF & Sig. \\
\hline There is a great demand for the one day surgery in the hospital. & 3.62 & 74.11 & *11.354 & 2 & 0.034 \\
\hline The patients are satisfied with the surgeries performed in the hospital. & 3.51 & 73.96 & $* 0.992$ & 2 & 0.017 \\
\hline $\begin{array}{l}\text { One day surgeries performed at the hospital are successful and do not result in } \\
\text { complications. }\end{array}$ & 3.66 & 74.23 & $* * 21.658$ & 2 & 0.000 \\
\hline There are no complaints of errors at the day surgery center in the hospital. & 3.80 & 67.02 & 9.008 & 2 & 0.000 \\
\hline Every patient is given adequate attention without discrimination. & 4.21 & 77.23 & 6.020 & 2 & 0.000 \\
\hline Different types of surgery are performed at the center and with a high quality. & 3.23 & 77.44 & 3.547 & 2 & 0.000 \\
\hline Total Mean & \multicolumn{5}{|c|}{3.67} \\
\hline
\end{tabular}

Note: *Significant at less than (0.05), **Significant at less than (0.01).

\section{Results of the Sixth Section}

The Fifth section of the questionnaire is about the retention of success of day surgery variable. Below are the responses of the participants to the items of this section:

The above Table 8 shows the responses to the success of day surgery. In general, the mean of all items (the success of day surgery) is (3.67) and the significance level is 0.000 . This indicates that the participants highly agree on the success of day surgery in the hospital. The results of the study show that one day surgery at PSMMC is very successful. The results showed that there is no complaint of any errors or complications in the surgical operations as well as a high demand for day surgery in the hospital. It is also shown that the patients are satisfied of the medical service in the day surgery clinics. This finding is in line with the findings of the Mitchell [4] that reported that day surgery units are one of the most important services in the modern health care facilities and with the results of the Beamont [1] which concluded that the management of the day surgery units should adopt the latest scientific techniques and methods in order to provide the best level of service and achieve the maximum success.

Table 8: Chi-square Results for the Factors Influencing the Success of Day Sugary at PSMMC.

\begin{tabular}{|c|c|c|c|c|}
\hline Factors Influencing the Success of Day Sugary & Mean & Chi-Square $\chi^{2}$ & DF & Sig. \\
\hline Administrative Procedures & 3.78 & $* 10.006$ & 2 & 0.002 \\
\hline Surgical Preparations & 3.22 & $* * 22.756$ & 2 & 0.000 \\
\hline Medical Staff & 3.41 & $* * 17.391$ & 2 & 0.000 \\
\hline laboratory and Radiology Preparations & 3.53 & $* 10.501$ & 2 & 0.000 \\
\hline Medical Care & 3.66 & $* 16.324$ & 2 & 0.000 \\
\hline
\end{tabular}

Note: *Significant at less than (0.05), **Significant at less than (0.01).

From the above Table 9, it is clear that the factors of (administrative procedures, surgical preparations, medical staff, laboratory and radiology preparations, and medical care) have a statistically significant correlation with the success of day surgery at PSMMC since the Chi-square values for all the variables are $(10.006,22.756,17.391,10.501$, and 16.324) and at a significance level less than (0.05).

\section{Conclusion}

The success of day surgery have been shown to be well connected and dependent of the factors selected in the current study. Firstly, the administrative procedures of day surgery at PSMMC are performed in a good manner in terms of the existence of a specific mechanism for the arrangement and coordination of surgery and patient's registration procedures that precede the surgery. Secondly, the surgical preparations in day surgery at PSMMC are performed in a good manner. The necessary tests and measurements are performed before the operation. The anesthesia options and the side effects of the patient are explained ensuring that the assistant surgeons, nurses and anesthesiologists are present and ready to work. Thirdly, the staff of day surgery units at PSMMC have a good level of qualifications.

They have a good level of scientific experience that suits the nature of their work. Fourthly, laboratory and radiation equipment in day surgery units in the hospital are well available. The patient can perform all types of medical tests in the hospital with the presence of various radiology devices and measurements, with the availability of modern equipment and the provision of the service quickly and without delay. Fifthly, medical care in day surgery units at PSMMC is provided in a distinguished manner where the nursing 
service is provided to the patients permanently with the provision of the necessary tools with continuous follow-up by the surgeon, the assistant doctors and the technicians as well as the guidance of the patients in relation to treatment instructions. Sixthly, the results showed that there is no complaint of any errors or complications as well as a high demand for day surgery in the hospital and high patients' satisfaction.

\section{Recommendations}

Based on the findings of this study, the researcher recommends the following:

1. The establishment of quality and development department of day surgeries in order to develop the facilities in day surgery units and introduce the technical systems that contribute to providing the service in a distinctive way.

2. Taking advantage of internationally known standards in the management of day surgery units to ensure the promotion of health services as well as protecting the health care providers and patients from any health risks.

3. The day surgery units in the hospital shall be independent in terms of medical staff and administrative procedures in order to facilitate procedures and improve the level of service.

4. Providing training courses to the health care providers in day surgery units to fit their work nature.

5. Increasing the number of day surgery clinics in the hospital to accommodate to the increasing demand.

\section{References}

1. Fehrrman K, Matthews C, Stocker M (2007) Day surgery in different guises: a comparison of outcomes. J One Day Surg 19: 39-42.

2. Khalil M, Al Eidi S, Al Qaed M, AlSanad S (2018) The future of integrative health and medicine in Saudi Arabia. Integrative medicine research 7(4): 316-321.

3. Suphanchaimat $R$, Thungthong J, Sriprasert $K$, Tisayaticom $K$, Limwattananon C (2019) Budget impact analysis of the new reimbursement policy for day surgery in Thailand. Risk management and healthcare policy, 12: 41-55.

4. Mitchell M (1997) Patients' perceptions of preoperative preparation for day surgery. Advanced Journal of Nursing, 26(2): 356-363.

5. Deng X, Liang S, Li H, Gouda D, Zhu T (2019) A cross-sectional study to assess the difference in perception of day surgery information between patients and medical staff in China. Patient preference and adherence 13: 381-387.

6. Andijany MA, AlAteeq MA (2019) Family medicine residents in central Saudi Arabia. How much do they know and how confident are they in performing minor surgical procedures? Saudi medical journal 40(2): 168-176.

7. Jegede FE, Mbah HA, Aminu M, Yakubu T, Torpey K (2015) Evaluation of Laboratory Performance with Quality Indicators in day case clinics. Open Journal of Clinical Diagnostics 5: 1-9.

8. Li L, Georgiou A, Vecellio E, Eigenstetter A, Toouli G (2015) The Effect of Laboratory Testing in day case clinics: A Multihospital Longitudinal Study Applying A Cross-classified Random-effect Modeling Approach. Academic Emergency Medicine 22(1): 38-46.
9. Ziab S (2012) Measurement of the quality of medical services provided in Jordanian public hospitals from the perspective of patients and employees. Journal of the Islamic University for Economic and Administrative Studies 20(1): 69-104.

10. Al Ahmadi T (2009) Assessment of the efficiency of the performance of health services in the Kingdom of Saudi Arabia. International Conference on Administrative Development, King Faisal Conference Hall, Riyadh pp. $1-4$.

11. Daar OB, Al Mutairi T (2018) How do patient demographics, timerelated variables, reasons for cancellation, and clinical procedures affect frequency of same-day operating room surgery cancelation? A maximum likelihood method. BMC health services research 18(1): 454.

12. Al Qahtani H, Alam, M, Asalamah, S, Akeely M, Ibrar M (2015) Day-case laparoscopic cholecystectomy. Saudi Med J 36(1): 46-51.

13. Currie MP, Karwatowski SP, Perera J, Langford E J (2004) Introduction of nurse led DC cardioversion service in day surgery unit: prospective audit. BMJ (Clinical research), 329(7471): 892-894.

14. Berg K, Kjellgren K, Unosson M, Arestedt K (2012) Postoperative recovery and its association with health-related quality of life among day surgery patients. BMC nursing, 11(1): 24.

15. Doran HE, England J, Palazzo F (2012) British Association of Endocrine and Thyroid Surgeons Questionable safety of thyroid surgery with same day discharge. Annals of the Royal College of Surgeons of England 94(8): 543-547.

16. Ansell GL, Montgomery JE (2004) Outcome of ASA III patients undergoing day case surgery. Br J Anaesth 92(1): 71-74.

17. Montgomery J (2013) How and why I use total intravenous anaesthesia (TIVA): a personal account. J One Day Surg 23: 69-70.

18. Davies KE, Houghton K, Montgomery JE (2001) Obesity and day-case surgery. Anaesthesia 56(11): 1112-1115.

19. Berg K, Årestedt K, Kjellgren K (2013) Post-operative recovery from the perspective of day surgery patients: a phenomenographic study. International Journal of Nursing Studies 50(12): 1630-1638.

20. Buckley H, Palmer J (2010) Overview of anaesthesia and patient selection for day surgery. Anaesthesia and Intensive Care Medicine 11(4): 147-152.

21. Doyle A, Saunders P (2009) Are patients well informed about their anaesthetic? Journal of One Day Surgery 19: 88-91.

22. Fraczyk L, Godfrey H (2010) Perceived levels of satisfaction with the preoperative assessment service experienced by patients undergoing general anaesthesia in a day surgery setting. Journal of Clinical Nursing 19(19-20): 2849-2859.

23. Chinamale $H$ (2010) An investigation of the status of quality assurance and quality control measures in X-ray departments in Malawi. A published master thesis. University of Johannesburg.

24. Odhiambo MA, Njuguna S, Waireri Onyango R, Mulimba J, Ngugi PM (2015) Utilization of day surgery services at Upper hill Medical Centre and the Karen hospital in Nairobi: the influence of medical providers, cost and patient awareness. The Pan African medical journal 22: 28.

25. Gilliard N, Eggli Y, Halfon P (2006) A methodology to estimate the potential to move inpatient to one day surgery. BMC health services research 6: 78.

26. Stessel B, Fiddelers AA, Joosten EA, Hoofwijk DM, Gramke HF (2015) Prevalence and Predictors of Quality of Recovery at Home After Day Surgery. Medicine 94(39): e1553.

27. Singarelli S, Berni A, Coppo G, Fracchia P (2005) Day-surgery, one-day surgery: the experience of an ENT unit in a 250-bed hospital. Acta Otorhinolaryngol Ital 25(6): 365-369.

28. Morsi E (2010) Statistical Approaches. Jordan: Thought House. 
ISSN: 2574-1241

DOI: 10.26717/BJSTR.2020.31.005174

Mohanned Khaled Almarzook. Biomed J Sci \& Tech Res

(C) This work is licensed under Creative

Submission Link: https://biomedres.us/submit-manuscript.php

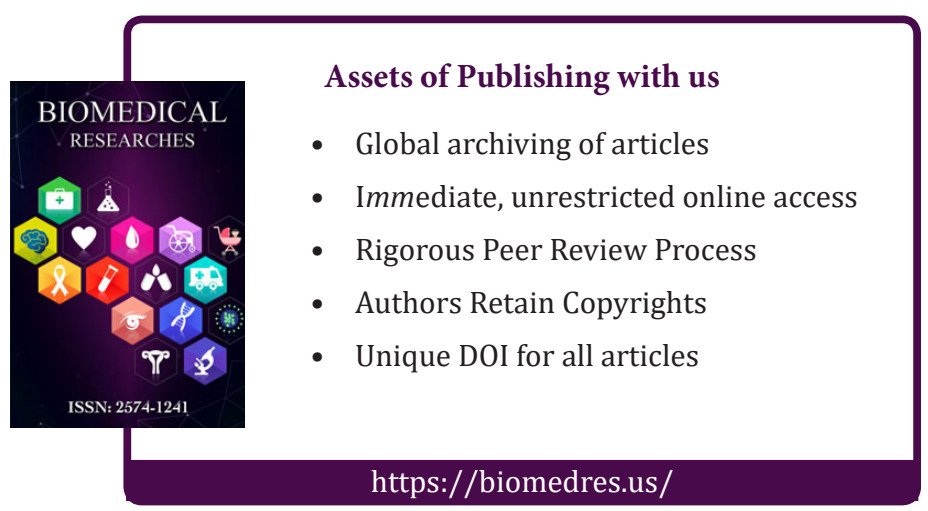

